\title{
The Effect of the 2009 USPSTF breast cancer screening recommendations on breast cancer in Michigan: A longitudinal study
}

\author{
Jamie Caughran MD, FACS ${ }^{1}$ (D) | Tom M. Braun PhD ${ }^{2}$ | Tara M. Breslin MD, FACS ${ }^{3}$ | \\ Daniel R. Smith PA-C $C^{4}$ Jennifer L. Kreinbrink PA-C $C^{4}$ | Grace K. Parish PA-C ${ }^{4}$ | \\ Alan T. Davis PhD ${ }^{4}$ Teresa A. Bacon-Baguley $\mathrm{PhD}^{4}$ | Samuel M. Silver MD, $\mathrm{PhD}^{2}$ | \\ Norah L. Henry MD, PhD 5
}

${ }^{1}$ Comprehensive Breast Center, Mercy Health Saint Mary's, Grand Rapids, MI, USA

${ }^{2}$ Rogel Cancer Center, University of

Michigan, Ann Arbor, MI, USA

${ }^{3}$ Comprehensive Breast Program, Mercy Health St. Joseph, Ann Arbor, MI, USA

${ }^{4}$ Physician Assistant Studies, Grand Valley State University, Allendale, MI, USA

${ }^{5}$ Division of Oncology, University of Utah, Salt Lake City, UT, USA

\section{Correspondence}

Jamie Caughran, Medical Director Comprehensive Breast Center, Lacks Center, Mercy Health, Grand Rapids, MI, USA.

Email: caughraj@mercyhealth.com

\begin{abstract}
In 2009, the revised United States Preventive Services Task Force (USPSTF) guidelines recommended against routine screening mammography for women age 4049 years and against teaching self-breast examinations (SBE). The aim of this study was to analyze whether breast cancer method of presentation changed following the 2009 USPSTF screening recommendations in a large Michigan cohort. Data were collected on women with newly diagnosed stage 0-III breast cancer participating in the Michigan Breast Oncology Quality Initiative (MiBOQI) registry at 25 statewide institutions from 2006 to 2015. Data included method of detection, cancer stage, treatment type, and patient demographics. In all, 30008 women with breast cancer detected via mammogram or palpation with an average age of 60.1 years were included. $38 \%$ of invasive cancers were identified by palpation. Presentation with palpable findings decreased slightly over time, from $34.6 \%$ in 2006 to $28.9 \%$ in 2015 $(P<.001)$. Over the 9-year period, there was no statistically significant change in rate of palpation-detected tumors for women age $<50$ years or $\geq 50$ years $(P=.27, .30$, respectively). Younger women were more likely to present with palpable tumors compared to older women in a statewide registry. This rate did not increase following publication of the 2009 USPSTF breast cancer screening recommendations.

KEYWORDS

method of breast cancer detection, palpable breast cancer, United States preventive services task force
\end{abstract}

\section{1 | INTRODUCTION}

Since 1990 , mortality rates due to breast cancer have been decreasing by $2.3 \%$ per year overall and by $3.3 \%$ for women $40-50$ years of age. ${ }^{1}$ The decrease in mortality has been attributed to early detection via screening mammography and improvements in systemic therapy. ${ }^{2}$ A significant benefit of mammography is the ability to detect cancer at an earlier stage, which may be a contributing factor to increased survival rates and decreased breast cancer recurrence. ${ }^{3,4}$ A reduction in breast cancer mortality rates due to teaching breast self-exam has not been confirmed. However, Mathis et al ${ }^{5}$ reported that a significant number of breast tumors (43\%) were initially detected through palpation by either the patient or clinician.

In 2009, the United States Preventive Services Task Force (USPSTF) revised their breast cancer screening recommendations. ${ }^{6}$ The most significant change was the recommendation against 
routine screening mammography for women $40-49$ years of age, which received a $\mathrm{C}$ grade. In addition, a recommendation against teaching self-breast examinations (SBE) was established in response to randomized studies indicating that teaching self-breast examinations had no impact on breast-cancer-related mortality and was associated with an increased risk of undergoing a benign breast biopsy. ${ }^{7}$ The recently published update to the recommendations again confirmed that routine screening mammography should not be performed in this population, but rather the decision should be made on an individual basis. ${ }^{8}$

The aim of this study was to analyze the method of breast cancer presentation before and after the USPSTF recommendations were released in 2009 for women seen at hospitals participating in the Michigan Breast Oncology Quality Initiative (MiBOQI) from 2006 to 2015.

\section{2 | METHODS}

Michigan breast oncology quality initiative (MiBOQI) is a multi-institution, statewide breast cancer registry that is a collaborative quality initiative sponsored by Blue Cross Blue Shield of Michigan/Blue Care Network. ${ }^{9,10}$ The MiBOQI registry contains over 300 data elements encompassing demographics, diagnosis, staging, and treatment; it does not include data prior to diagnosis. Follow-up data are obtained 4, 9, 18, and 30 months after initial diagnosis.

We analyzed data for women diagnosed with stage 0-III breast cancer between 2006 and 2015 from 25 medical institutions with at least 270 days follow-up (to allow capture of chemotherapy and radiotherapy). Patients with missing data in any of the following fields were excluded from analysis: (i) Age at diagnosis, (ii) Breast cancer presentation, and (iii) TNM Stage (Figure 1). The breast cancer presentation was classified into 3 groups: (i) Mammography, (ii) Palpation during breast examination (either self or clinician) and, (iii) Other. The "Other" presentations category included bloody nipple discharge, inverted nipple, axillary mass, or breast pain/discomfort. Only women whose cancers were identified through either palpation or mammography were included in the analysis.

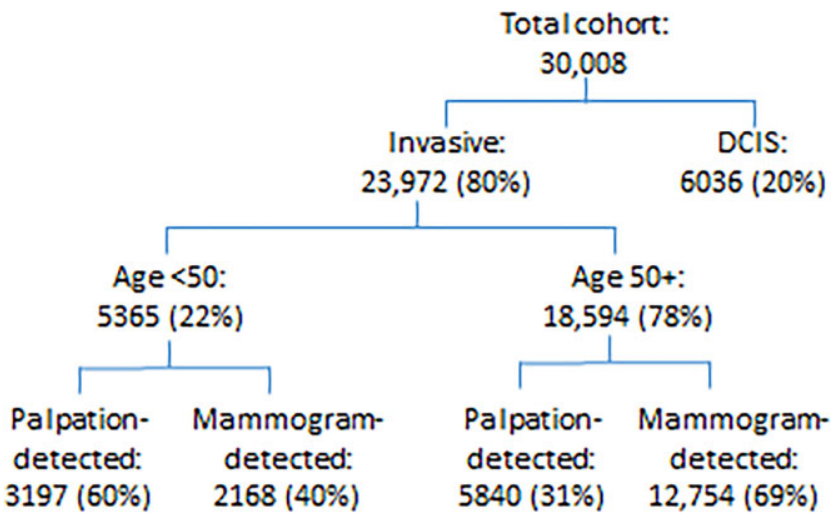

FIGURE 1 Exclusion criteria diagram [Color figure can be viewed at wileyonlinelibrary.com]
All data were de-identified prior to analysis. This study was approved by the Institutional Review Board at Grand Valley State University, Allendale, Michigan (Approval \#175143-1). The statistical software packages SAS and R were used to analyze and compare method of detection with categorical variables (ie, TNM staging and surgical management) and continuous variables (ie, age at the time of initial diagnosis). Chi-square tests and 2 sample $t$ tests were used, respectively. A statistically significant $P$ value was considered to be $P<.05$.

\section{3 | RESULTS}

\section{1 | Disease presentation}

In all, 30008 women met study criteria. Patient demographic and staging data are summarized in Table 1 . The average age at of diagnosis was 60.1 years [standard deviation (SD) 12.9]. DCIS without invasive breast cancer was diagnosed in 6036 patients. In the 23972 patients in the invasive cohort, 14929 (62.3\%) had mammographically detected tumors, and 9041 (37.7\%) presented with a palpable tumor. Of the patients with palpable tumors, $87.0 \%$ were detected through self-examination, $8.4 \%$ were detected by clinician examination, and 4.6\% had other presenting clinical symptoms (Figure 1).

Presentation with palpable findings decreased slightly over time in the entire cohort, from $34.6 \%$ in 2006 to $28.9 \%$ in 2015 $(P<.001$, Figure 2$)$. For women under age 50 years, the rate of cancer detection by palpation decreased from $67 \%$ in 2006 to $54 \%$ in 2015 , which was not a statistically significant decrease $(P=.27$; Figure 3). For women age 50 years and over, the rate remained essentially stable, and was $29 \%$ in 2006 and $30 \%$ in 2015 ( $P=.30$, Figure 3). Across the 25 participating MiBOQI sites, there was a statistically significant $(P<.001)$ variation in rates of palpation-detected tumors (Figure 4 ), which varied from $24 \%$ to $45 \%$.

\subsection{Associations between disease presentation and clinicopathologic characteristics}

Compared to patients with invasive cancer who had mammographically detected tumors, patients with a palpable tumor at presentation were more likely to be younger, black race, and insured by commercial (non-Medicare) plans or Medicaid. They are also more likely to have higher stage disease, higher tumor grade, ductal histology, lack ER and PR expression, and have HER2 overexpression or amplification (Table 2). On multivariate analysis, all of these factors remained statistically significant, with the exception of race and HER2 overexpression.

When specifically examining patients under age 50 years, compared to those with mammographically detected tumors, patients with a palpable tumor at presentation were more likely to be black race, insured by Medicaid, have higher clinical stage disease, and have tumors with higher grade, ER and PR negativity, and HER2 overexpression $P<.001$ (Table 3 ). On multivariate analysis, only higher clinical stage remained statistically significant. 
TABLE 1 Demographic and clinicopathologic characteristics of the entire cohort

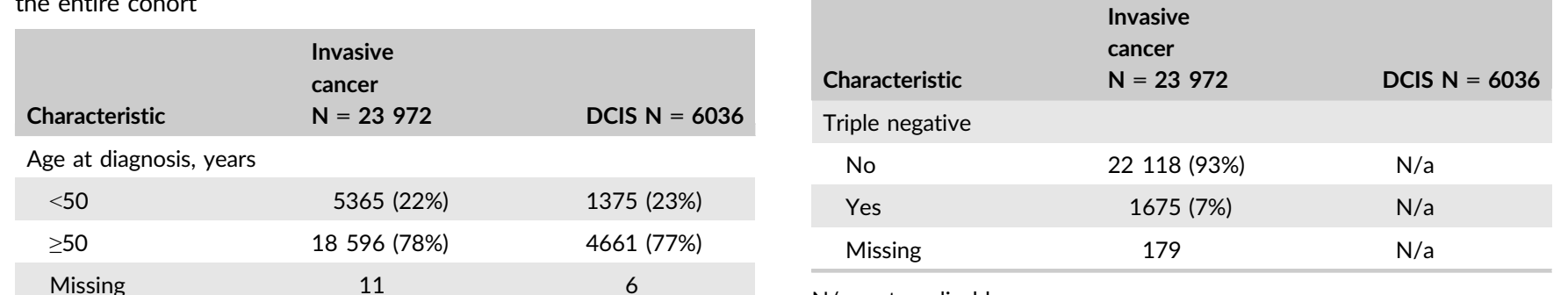

11

TABLE 1 (Continued)
Race

\begin{tabular}{lcc} 
Black & $3113(13 \%)$ & $872(14 \%)$ \\
White & $19414(81 \%)$ & $4770(79 \%)$ \\
Other & $1445(6 \%)$ & $400(7 \%)$ \\
\hline Insurance payor & &
\end{tabular}

Insurance payor

$\begin{array}{lcc}\text { Commercial } & 10511(55 \%) & 2933(61 \%) \\ \text { Government } & 116(1 \%) & 18(0 \%) \\ \text { Medicaid } & 1154(6 \%) & 203(4 \%) \\ \text { Medicare } & 7282(38 \%) & 1635(34 \%) \\ \text { Other } & 39(0 \%) & 17(0 \%) \\ \text { Uninsured } & 78(0 \%) & 9(0 \%) \\ \text { Missing } & 4792 & 1227\end{array}$

Clinical stage

\begin{tabular}{crl} 
Stage 0 & \multicolumn{1}{c}{$\mathrm{N} / \mathrm{a}$} & $6042(100 \%)$ \\
Stage I & $13722(57 \%)$ & $\mathrm{N} / \mathrm{a}$ \\
Stage II & $7840(33 \%)$ & $\mathrm{N} / \mathrm{a}$ \\
\hline Stage III & $2410(10 \%)$ & $\mathrm{N} / \mathrm{a}$ \\
Histologic grade & & \\
Grade 1 & $6069(26 \%)$ & $\mathrm{N} / \mathrm{a}$ \\
Grade 2 & $10106(44 \%)$ & $\mathrm{N} / \mathrm{a}$ \\
Grade 3 & $7004(30 \%)$ & $\mathrm{N} / \mathrm{a}$ \\
Other & $25(0 \%)$ & $\mathrm{N} / \mathrm{a}$ \\
Missing & 768 & $\mathrm{~N} / \mathrm{a}$
\end{tabular}

Surgery

$\begin{array}{lrc}\text { BCS } & 15268(64 \%) & 4409(73 \%) \\ \text { Mastectomy } & 8285(35 \%) & 1573(26 \%) \\ \text { Other } & 419(2 \%) & 60(1 \%)\end{array}$

Estrogen receptor positive

$\begin{array}{lcc}\text { No } & 4243(18 \%) & \mathrm{N} / \mathrm{a} \\ \text { Yes } & 19628(82 \%) & \mathrm{N} / \mathrm{a} \\ \text { Missing } & 101 & \mathrm{~N} / \mathrm{a}\end{array}$

Progesterone receptor positive

$\begin{array}{lcl}\text { No } & 6452(27 \%) & \mathrm{N} / \mathrm{a} \\ \text { Yes } & 17364(73 \%) & \mathrm{N} / \mathrm{a} \\ \text { Missing } & 156 & \mathrm{~N} / \mathrm{a} \\ \text { HER2 positive } & & \\ \text { No } & 20728(87 \%) & \mathrm{N} / \mathrm{a} \\ \text { Yes } & 3206(13 \%) & \mathrm{N} / \mathrm{a} \\ \text { Missing } & 38 & \mathrm{~N} / \mathrm{a} \\ & & \text { (Continues) }\end{array}$

N/a, not applicable.

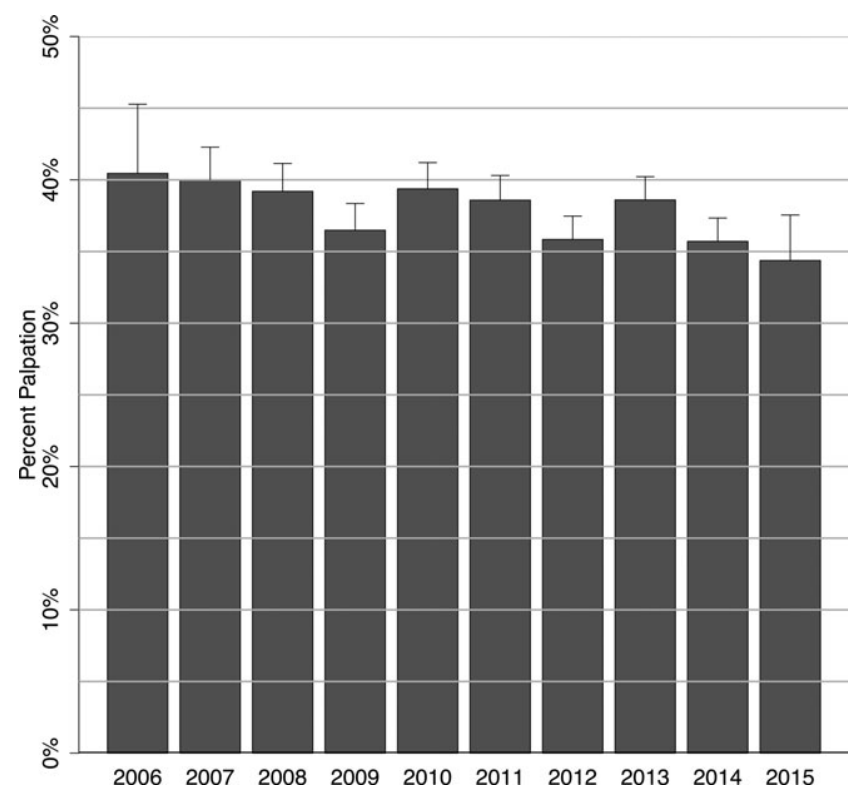

FIGURE 2 Percent of patients with tumors diagnosed by palpation, by year

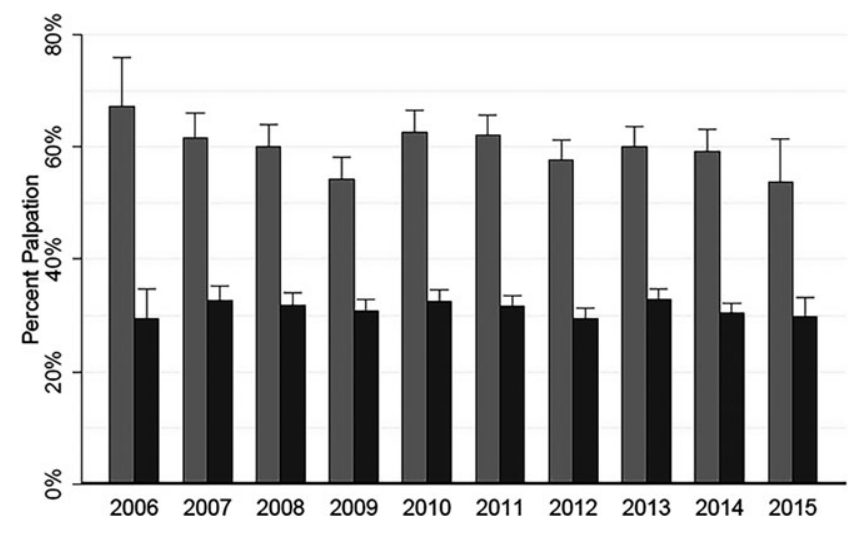

FIGURE 3 Percent of patients with tumors diagnosed by palpation age $<50, \geq 50$ by year

Comparison of patients age 50 years and older with a palpable tumor vs a mammographically detected tumor at presentation yielded similar results. Patients with palpable tumors were more likely to be black race, insured by Medicaid, have higher clinical stage disease, and have tumors with higher grade, ER and PR 


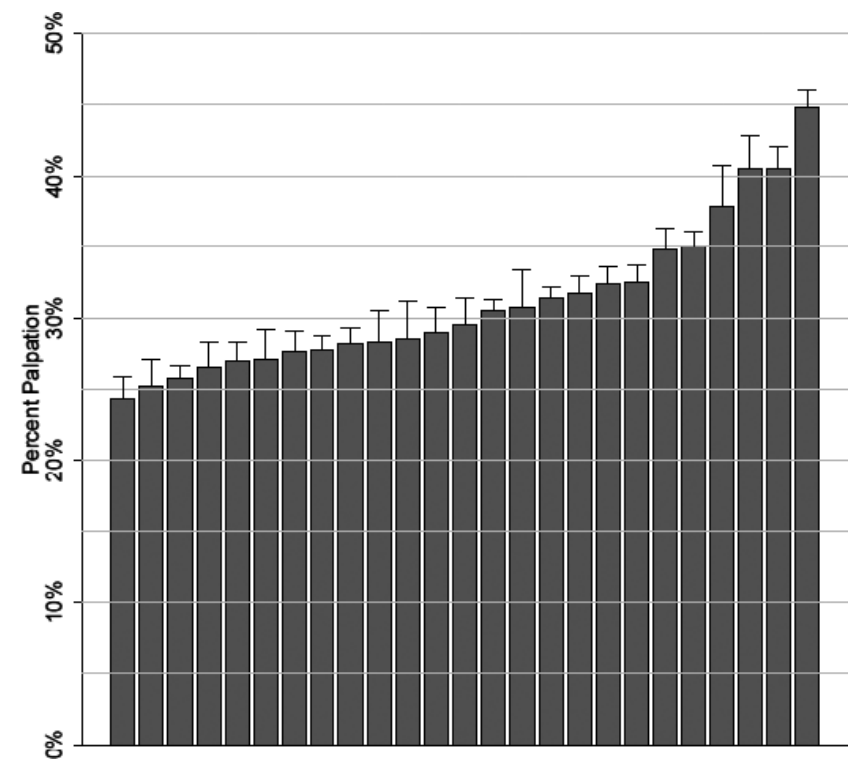

FIGURE 4 Percent of patients with tumors diagnosed by palpation, by michigan breast oncology quality initiative participating site negativity, and HER2 overexpression $P<.001$ (Table 3). On multivariate analysis, only insurance payor, stage, surgery type, and PR negativity remained statistically significant.

On univariate analysis, comparing patients under age 50 years with older women, there were associations between method of detection of the tumor and insurance payor, clinical stage, type of surgery, and PR overexpression (Table 3). The association between other factors, including race, tumor grade, and histology, and method of detection of the tumor did not differ between the age groups.

\section{4 | DISCUSSION}

In this contemporary cohort of 30008 breast cancer patients, approximately one-third of patients presented with a palpable tumor, and this rate decreased slightly over time from 2006 to 2015. Women with palpable cancers were younger and presented with more advanced tumor stages and more aggressive tumor profiles than those with mammography-detected cancers. Our results are concordant with prior reports in the literature. ${ }^{5}$

TABLE 2 Multivariate analysis of associations between demographic and clinicopathologic characteristics and method of breast cancer detection

\begin{tabular}{|c|c|c|c|c|}
\hline Characteristic & Palpation N = 9041 & Mammogram N = 14929 & Univariate $P$ value & Multivariate $P$ value \\
\hline \multicolumn{5}{|c|}{ Age at diagnosis, years } \\
\hline$<50$ & 3197 (35\%) & $2168(15 \%)$ & \multirow[t]{2}{*}{$<.001$} & \multirow[t]{2}{*}{$<.001$} \\
\hline Missing & 4 & 7 & & \\
\hline \multicolumn{5}{|l|}{ Race } \\
\hline White & 7032 (78\%) & 12380 (83\%) & \multirow{2}{*}{$<.001$} & \multirow{2}{*}{.2980} \\
\hline Other & $601(7 \%)$ & $844(6 \%)$ & & \\
\hline \multicolumn{5}{|l|}{ Insurance payor } \\
\hline Commercial & $4232(58 \%)$ & $6279(53 \%)$ & \multirow[t]{4}{*}{$<.001$} & \multirow[t]{4}{*}{$<.001$} \\
\hline Government & 40 (1\%) & $76(1 \%)$ & & \\
\hline Uninsured & $52(1 \%)$ & $26(0 \%)$ & & \\
\hline Missing & 1795 & 2997.00 & & \\
\hline \multicolumn{5}{|l|}{ Clinical stage } \\
\hline Stage I & $2782(31 \%)$ & $10940(73 \%)$ & \multirow[t]{3}{*}{$<.001$} & \multirow[t]{3}{*}{$<.001$} \\
\hline Stage II & $4556(50 \%)$ & $3282(22 \%)$ & & \\
\hline Stage III & $1703(19 \%)$ & 707 (5\%) & & \\
\hline \multicolumn{5}{|l|}{ Tumor grade } \\
\hline Grade 1 & $1325(15 \%)$ & $4744(33 \%)$ & \multirow[t]{2}{*}{$<.001$} & \multirow[t]{2}{*}{$<.001$} \\
\hline Grade 2 & $3518(40 \%)$ & $6588(46 \%)$ & & \\
\hline
\end{tabular}


TABLE 2 (Continued)

\begin{tabular}{|c|c|c|c|c|}
\hline Characteristic & Palpation N = 9041 & Mammogram N = 14929 & Univariate $P$ value & Multivariate $P$ value \\
\hline Grade 3 & 3915 (45\%) & $3088(21 \%)$ & & \\
\hline Other & $9(0 \%)$ & $15(0 \%)$ & & \\
\hline Missing & 274 & 494 & & \\
\hline \multicolumn{5}{|l|}{ Histology } \\
\hline Invasive ductal & 7711 (85\%) & 12432 (83\%) & $<.001$ & .0272 \\
\hline Invasive ductal and lobular & $173(2 \%)$ & $331(2 \%)$ & & \\
\hline Invasive lobular & $882(10 \%)$ & $1569(11 \%)$ & & \\
\hline Other & $275(3 \%)$ & $597(4 \%)$ & & \\
\hline \multicolumn{5}{|l|}{ Missing } \\
\hline \multicolumn{5}{|l|}{ Estrogen receptor positive } \\
\hline No & $2338(26 \%)$ & $1903(13 \%)$ & $<.001$ & $<.001$ \\
\hline Yes & $6664(74 \%)$ & 12964 (87\%) & & \\
\hline Missing & 39 & 62 & & \\
\hline \multicolumn{5}{|l|}{ Progesterone receptor positive } \\
\hline No & 3183 (35\%) & 3267 (22\%) & $<.001$ & .0064 \\
\hline Yes & $5810(65 \%)$ & 11554 (78\%) & & \\
\hline Missing & 48 & 108 & & \\
\hline \multicolumn{5}{|l|}{ HER2 positive } \\
\hline No & 7469 (83\%) & 13258 (89\%) & $<.001$ & .3739 \\
\hline Yes & 1549 (17\%) & $1656(11 \%)$ & & \\
\hline Missing & 9 & 3 & & \\
\hline Triple negative & 48 & 108 & & \\
\hline No & 8217 (91\%) & 13899 (94\%) & $<.001$ & $\mathrm{~N} / \mathrm{a}$ \\
\hline Yes & 765 (9\%) & $910(6 \%)$ & & \\
\hline Missing & 23 & 15 & & \\
\hline \multicolumn{5}{|l|}{ Surgery } \\
\hline BCS & 4449 (49\%) & $10817(72 \%)$ & $<.001$ & $<.001$ \\
\hline Mastectomy & 4340 (48\%) & 3945 (26\%) & & \\
\hline Other & 252 (3\%) & 167 (1\%) & & \\
\hline
\end{tabular}

TABLE 3 Univariate analysis of associations between demographic and clinicopathologic characteristics and patient age at time of breast cancer diagnosis

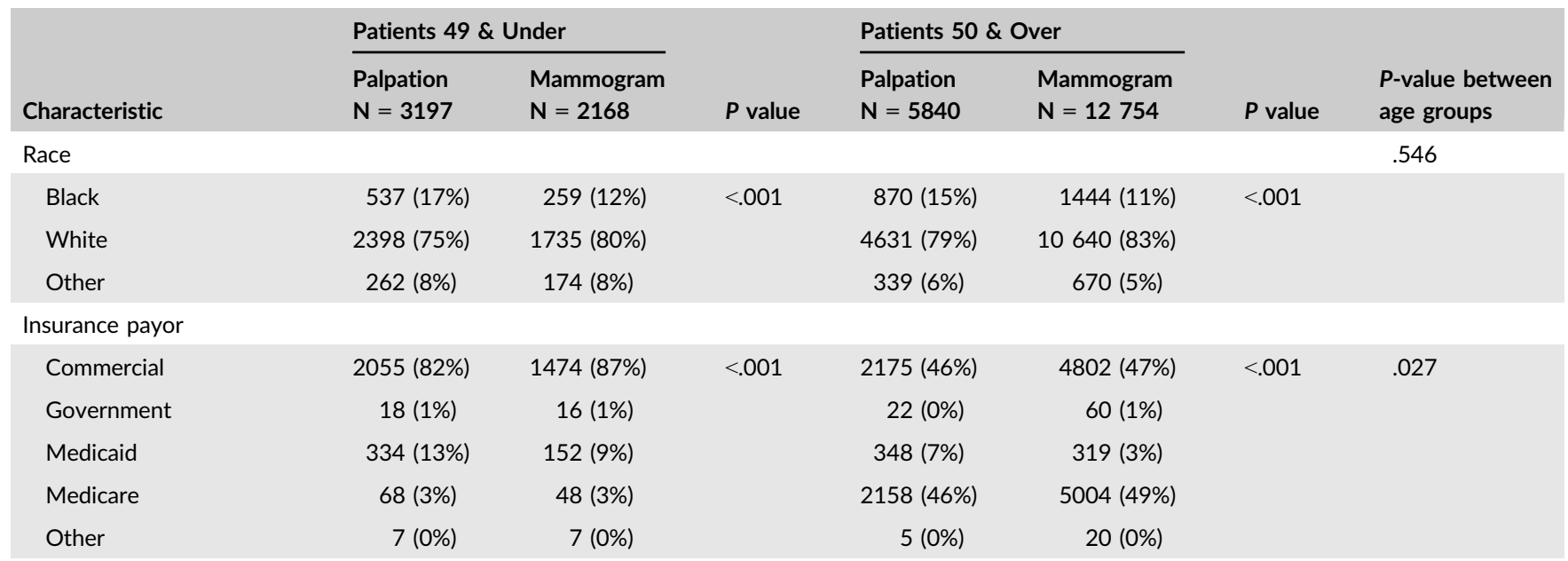


TABLE 3 (Continued)

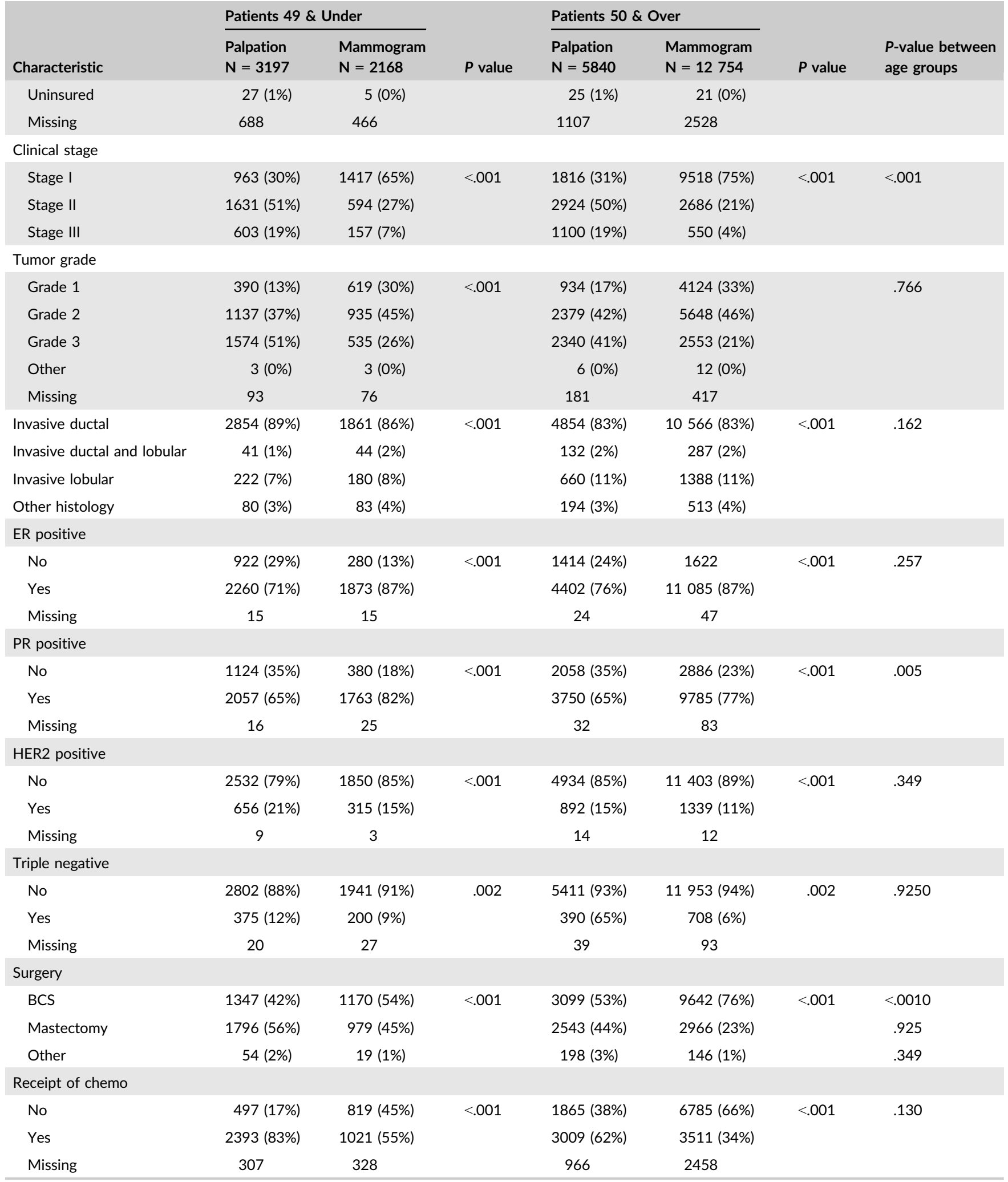

The impact the 2009 USPSTF screening recommendations have had on cancer presentation is unknown. A review of screening mammography utilization by Sharpe et al $^{11}$ in the Medicare population noted a decrease in $4.3 \%$ in 2010 in this older population after seeing annual growth of $0.5 \%$ prior to the 2009 recommendations. In contrast, using claims data, a smaller decrease in screening 
mammography use of $1.2 \%$ was identified in a cohort of insured women under the age of 50 years. ${ }^{12}$ In our MiBOQl cohort of women under 50 years, no compensatory increase in palpable tumors was noted after the 2009 recommendations, but rather the rate remained relatively stable. The reason for this finding is uncertain, but likely multifactorial. One potential explanation is that screening mammography rates may have remained relatively unchanged despite the 2009 guidelines. In particular, the enactment of the Affordable Care Act may have enabled more women of all ages to undergo screening mammography, thereby offsetting changes related to less aggressive screening recommendations. However, as noted below, we are unable to assess this possibility in our cohort because of limitations of the MiBOQI Registry. If screening rates did in fact decline, then the inability to diagnosis more of the indolent tumors was not seen, as demonstrated by a compensatory increase in palpable method of detection, within the time frame of the study.

Our study only included women with a breast cancer diagnosis and did not include the general screening population, so no comparisons can be made regarding screening efficacy. Data collected represent only a snapshot of each patient's presentation without information on previous screening practices. Conflicting recommendations have been made regarding the age at which to initiate screening mammography. Work by Hayse et $\mathrm{al}^{13}$, suggest that screen-detected tumors have more indolent biology than cancers with a palpable presentation. In our cohort, palpable tumors were more likely to be ER negative or HER2 positive amongst women of all age groups. However, information regarding whether these tumors represent interval cancers between mammograms or if they were mammographically occult was not captured in the Registry. In a study by Bellio et $\mathrm{al}^{14}, 20 \%$ of patients in a mammographic screening program presented with interval breast cancers, and these tumors had worse prognostic features and clinical outcomes than screen-detected tumors. These findings further strengthen the argument that women and clinicians should not rely on mammography alone for breast cancer detection. A considerable strength of this analysis is the large size of the cohort, which is derived from practices that are heterogeneous, and reflect community- and academicbased practices, urban, suburban, and rural areas, and communities with low and high socioeconomic status. In this statewide registry, we demonstrate that that there is considerable variability across hospital systems in method of breast cancer presentation. This variability could be due to differences in practice patterns across the state, or could reflect differences in patient mix at different institutions.

During this time period regardless of healthcare policy changes, $22.3 \%$ of the cancers in this cohort were in women under the age of 50 years, and these women presented with palpable tumors at a much greater frequency than those over the age of 50 years. A higher stage of presentation, more aggressive biology, and more extensive surgical management then follows in younger women. Clinicians should consider these data when determining the impact screening recommendations will have on their patient population.

\section{5 | CONCLUSION}

This cohort demonstrates no increase in the diagnosis of breast cancer because of presentation with palpable findings following the USPSTF 2009 recommendations based on comparison of rates for 3 years before and 6 years after their publication. These multi-institutional data derived from a large Registry cohort provide a robust view of the clinical presentation of breast cancer in a modern cohort. Women with breast cancer detected by mammography presented with earlier stage disease in all age groups and often underwent less aggressive local therapy. Women under the age of 50 years, who accounted for almost one-quarter of the Registry cohort, were more likely to present with a palpable mass although this rate did not increase following the 2009 recommendations. These findings underscore the importance of recognizing and thoroughly evaluating of breast masses and breast symptoms in this population.

\section{ORCID}

Jamie Caughran (iD http://orcid.org/0000-0003-4260-0234

\section{REFERENCES}

1. American Cancer Society. Breast Cancer Facts \& Figures 2009-2010. Atlanta, GA: American Cancer Society, Inc.; 2009. Available at: http://www.cancer.org/Cancer/BreastCancer/OverviewGuide/brea st-cancer- overview-key-statistics. Accessed: January 15, 2011

2. Peto R, Boreham J. ClarkeM, Davies C, Beral V. UK and USA breast cancer deaths down $25 \%$ in year 2000 at ages 20-69 years. Lancet. 2000;355:1822.

3. Burrell HC, Pinder SE, Wilson ARM, et al. The positive predictive value of mammographic signs: a review of 425 non-palpable breast lesions. Clin Radiol. 1996;51:277-281.

4. Senie RT, Lesser M, Kinne DW, Rosen PP. Method of tumor detection influences disease-free survival of women with breast carcinoma. Cancer. 1994;73:1666-1672.

5. Mathis KL, Hoskin TL, Boughey JC, et al. Palpable presentation of breast cancer persists in the era of screening mammography. J Am Coll Surg. 2010;210:314-318.

6. US Preventive Services Task Force. Screening for breast cancer: US Preventive Services Task Force recommendation statement. Ann Intern Med. 2009;151:716-726.

7. Thomas DB, Gao DL, Ray RM, et al. Randomized trial of breast selfexamination in shanghai: final results. J Natl Cancer Inst. 2002;94:1445-1457.

8. Siu AL, US Preventive Services Task Force. Screening for Breast Cancer: U.S. Preventive Services Task Force Recommendation Statement. Ann Intern Med. 2016;164:279-296.

9. Silver SM, Mehringer M, Hayes A, et al. Michigan Breast Oncology Quality Initiative (MiBOQI): A state-wide multidisciplinary breast cancer quality initiative - Concordance with quality measures. 2009 Breast Cancer Symposium, Abstract No. 164, San Francisco, CA. October 8-10, 2009.

10. Henry NL, Braun TM, Breslin TM, et al. Variation in the use of advanced imaging at the time of breast cancer diagnosis in a statewide registry. Cancer. 2017;123:2975-2983.

11. Sharpe RE Jr, Levin DC, Parker L, Rao VM. The effect of the controversial us preventive services task force recommendations on the use of screening mammography. J Am Coll Radiol. 2016;13(11 Suppl): e58-e61. 
12. Qin X, Tangka FK, Guy GP Jr, Howard DH. Mammography rates after the 2009 revision to the United States Preventive Services Task Force breast cancer screening recommendation. Cancer Causes Control. 2017;28:41-48.

13. Hayse B, Hooley RJ, Killelea BK, et al. Breast cancer biology varies by method of detection and may contribute to overdiagnosis. Surgery. 2016;160:454-462.

14. Bellio G, Marion R, Giudici F, et al. Interval breast cancer versus screen-detected cancer: comparison of clinicopathologic characteristics in a single-center analysis. Clin Breast Cancer. 2017;17:564-571.
How to cite this article: Caughran J, Braun TM, Breslin TM, et al. The Effect of the 2009 USPSTF breast cancer screening recommendations on breast cancer in Michigan: $A$ longitudinal study. Breast J. 2018;24:730-737.

https://doi.org/10.1111/tbj.13034 